\title{
Seismic vulnerability assessment of a continuous steel box girder bridge considering influence of LRB properties
}

\author{
TAE-HYUNG LEE ${ }^{1}$ and DUY-DUAN NGUYEN ${ }^{1,2, *}$ \\ ${ }^{1}$ Department of Civil Engineering, Konkuk University, 120 Neudong-ro, Gwangjin-gu, Seoul 05029, South \\ Korea \\ ${ }^{2}$ Department of Civil Engineering, Vinh University, 182 Le Duan, Vinh 460000, Vietnam \\ e-mail: duan468@gmail.com
}

MS received 21 July 2016; revised 30 May 2017; accepted 4 June 2017; published online 7 February 2018

\begin{abstract}
Bridges are one of the most crucial facilities of transportation networks. Therefore, evaluation of the seismic vulnerability of bridge structures is perpetually regarded topic for researchers. In this study, we developed seismic fragility curves for a continuous steel box girder bridge considering the effect of different levels of mechanical properties of lead rubber bearing (LRB) devices including initial stiffness and yield strength on the seismic performance of such structure. A powerful framework for an earthquake engineering simulation, OpenSees, is used to perform nonlinear analyses of the bridge model. In order to construct fragility curves for this structure, a set of 20 ground acceleration records is adopted and various scales of the peak ground acceleration (PGA) from 0.1 to $1.6 \mathrm{~g}$ are considered. Besides, a series of damage state of the bridgeis defined based on a damage index, which is expressed in terms of the column displacement ductility ratio. Fragility analyses result reveals that reducing the initial stiffness of LRBs reduces the seismic vulnerability of bridge piers and vice versa. Meanwhile, the changes of the yield strength of LRBs have trivially effected on the seismic behaviour of the bridge piers. On the other hand, the short pier has performed more susceptibly than those of the high pier in both seismically-isolated and non-isolated bridge cases. Lastly, the results in this research also indicate that the bridge structures equipped with seismic isolation devices (e.g. LRBs) significantly mitigated the damages due to earthquakes.
\end{abstract}

Keywords. Continuous steel box girder bridge; fragility curves; seismic vulnerability assessment; damage state; nonlinear dynamic analysis; lead rubber bearing.

\section{Introduction}

In recent years, fragility analysis has been a dominant tool for a seismic vulnerability assessment of infrastructures such as bridges and buildings. Many studies developed fragility curves for the structures not only based on empirical methods but also analytical procedures. Empirical fragility curves are derived based on damage data that observed from specific post-earthquake events. However, developing fragility functions from empirical observations sometimes encounter challenges due to lack of sufficient damage data caused by past earthquakes. In an alternative way, fragility curves can be constructed by applying some analytical procedures such as elastic spectral analysis, nonlinear static analysis, and nonlinear time-history analysis methods [1, 2]. Among these analytical methods, nonlinear time history analysis is the most widely used and the most reliable method for deriving fragility curves of structures [2, 3].

*For correspondence
Previously, a number of researchers constructed fragility curves for seismic vulnerability evaluation of bridge structures using the nonlinear dynamic method. Karim and Yamazaki [4] developed fragility curves for four typical reinforced concrete (RC) bridge piers and two RC bridge structures which were designed and constructed in Japan. The nonlinear time history analyses were implemented and a set of damage index for the bridges was achieved by using the definition of Park-Ang damage model [5]. A simplified procedure for constructing the analytical fragility curves of highway bridges was also proposed in this research. Choi et al [6] generated a set of fragility curves for four typical bridges including multi-span simply supported steel girder bridge, multi-span continuous steel girder bridge, multispan simply supported pre-stressed concrete girder bridge and multi-span continuous pre-stressed concrete girder bridge in the Central and Southeastern United States that is considered as moderate seismic zones. The fragility analyses lead to the conclusion that the multi-span simply supported and multi-span continuous steel-girder bridges are the most vulnerable bridge types. Kibboua et al [7] 


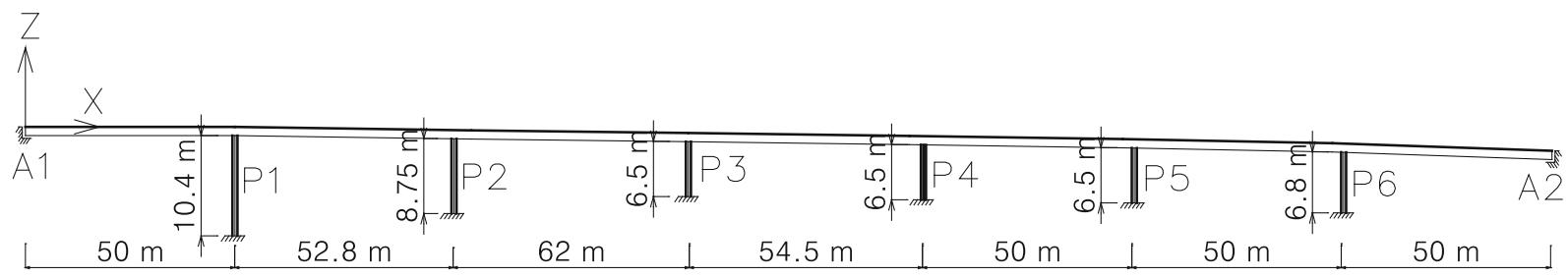

Figure 1. Elevation view of the bridge.

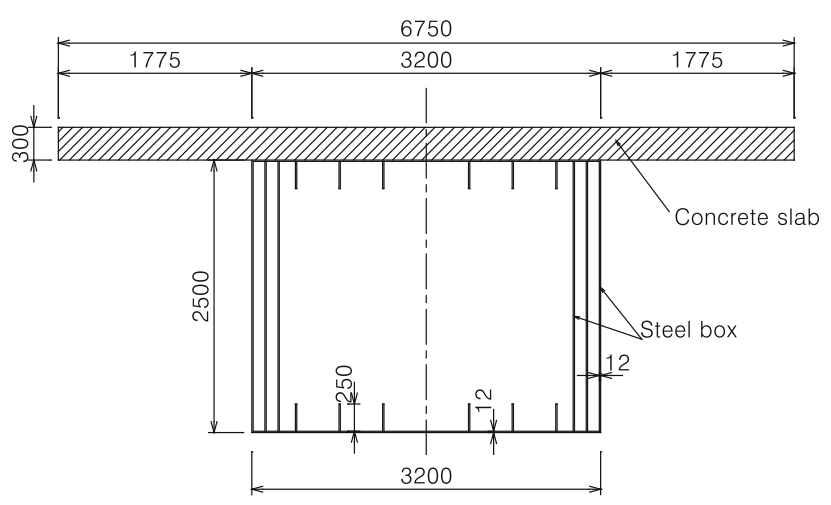

Figure 2. Cross-section of the bridge girder.

derived the fragility curves for four typical Algerian RC bridge piers that consist of the circular pier, hollow core pier, wall pier and hammerhead pier types. Tavares et al [8] evaluated seismic vulnerability of the Chemin des Dalles Bridge in Quebec, Canada through fragility curves of the bridge column, elastomeric bearing, and abutment wall. Lee et al [9] developed fragility curves for bridges in Korea. To achieve this purpose, they classified atotal of 1008 highway bridges into eight bridge groups and adopted logistic curves equations to express relationships between PGAs and vulnerability levels.
In order to diminish the seismic risk and enhance the seismic performance of bridge structures, various elastomeric bearing devices such as LRBs and high damper rubber bearings have been used. The effect of based isolation systems on seismic performances of bridge structures is evaluated through seismic fragility curves. Karim and

Table 1. Concrete material properties.

\begin{tabular}{lcccccc}
\hline & $\begin{array}{c}f_{p c} \\
(\mathrm{Mpa})\end{array}$ & $\varepsilon_{c o}$ & $\begin{array}{c}f_{p c u} \\
(\mathrm{MPa})\end{array}$ & $\varepsilon_{u}$ & $\begin{array}{c}f_{t} \\
(\mathrm{MPa})\end{array}$ & $\begin{array}{c}E_{t s} \\
(\mathrm{GPa})\end{array}$ \\
\hline $\begin{array}{c}\text { Confined } \\
\text { concrete }\end{array}$ & 40.8 & 0.004 & 34.2 & 0.02 & 4.0 & 0.55 \\
$\begin{array}{c}\text { Unconfined } \\
\text { concrete }\end{array}$ & 27.2 & 0.002 & 6.8 & 0.002 & 4.0 & 1.22 \\
\hline
\end{tabular}

Table 2. Steel material properties.

\begin{tabular}{ccccccc}
\hline & $F_{y}(\mathrm{Mpa})$ & $E_{s}(\mathrm{GPa})$ & $b$ & $R_{0}$ & $C_{R 1}$ & $C_{R 2}$ \\
\hline Steel & 408 & 197 & 0.01 & 18 & 0.925 & 0.15 \\
\hline
\end{tabular}
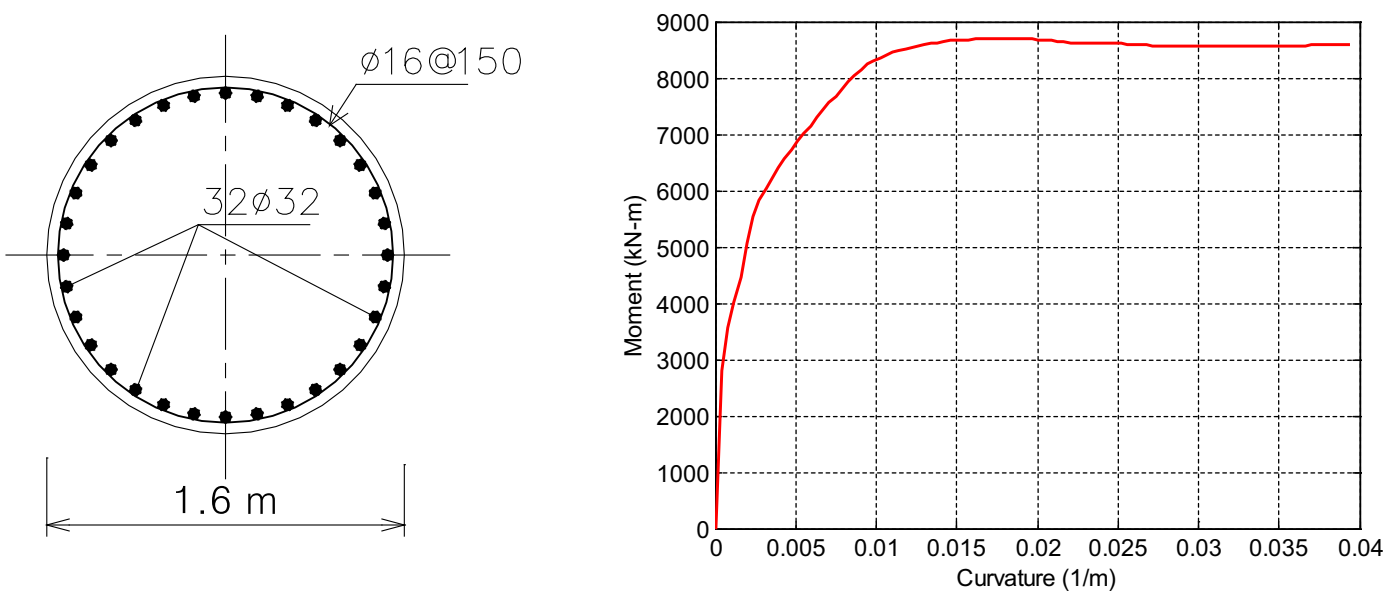

Figure 3. Cross-section and moment-curvature relationship of the bridge columns. 


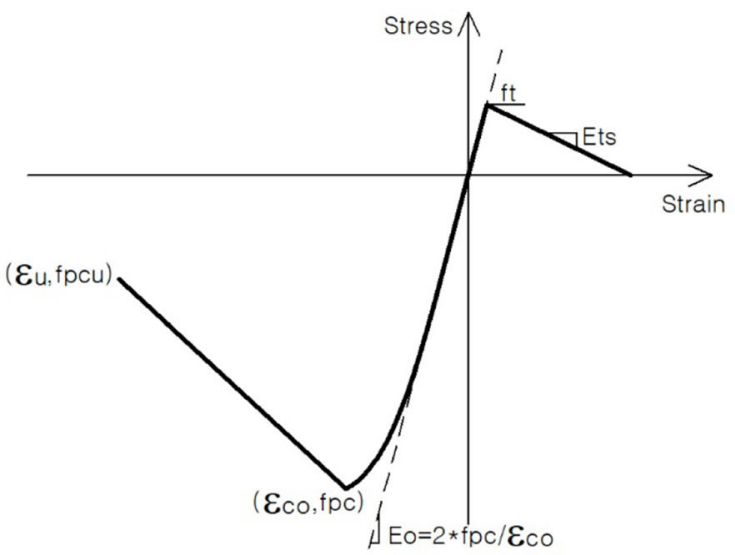

(a)

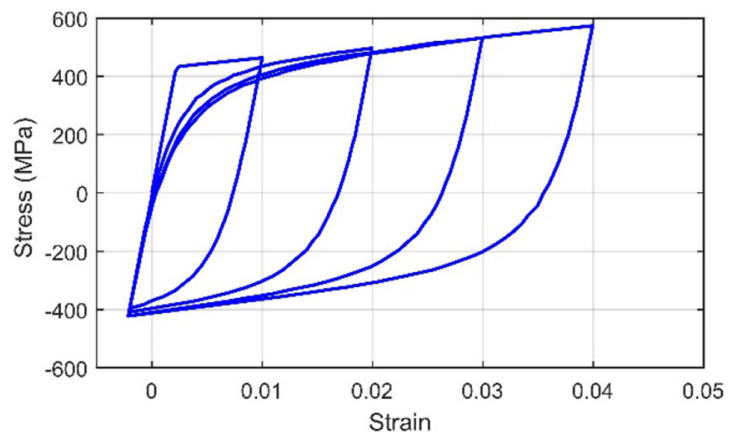

(b)

Figure 4. Concrete02 (a) and SteelO2 (b) models in OpenSees.

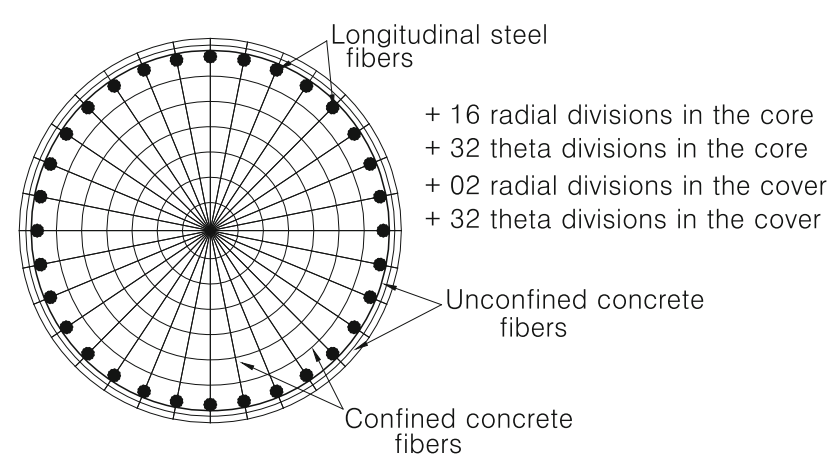

Figure 5. Fiber section model for the bridge pier elements.

Yamazaki [4] showed the comparison of the fragility curves for the isolated and non-isolated bridge systems. It revealed that at a specific value of peak ground acceleration (PGA) the damage probability for the non-isolated bridge is larger than those of the isolated one. Kim et al [10] assessed the seismic risk of an extradosed bridges with and without LRB devices. Based on the analysis results, it can be seen that in seismically-isolated extradosed bridges the influence of LRBs is more significant in the columns than the other structural members such as girders and cables. Ramanathan et al [11] developed and compared fragility curves for seismically and non-seismically designed bridges which are the multi-span continuous steel girder bridge types in the Central and Southeastern United States. They concluded that using elastomeric bearings pads instead of steel rocker bearings improved the seismic performance of the bridge structure in the higher damage states when compared with those of the non-seismic model. Alam et al [12] obtained the seismic fragility curves for a continuous bridge equipped with laminated rubber bearings and shape memory alloy restrainers. Two kinds of laminated rubber bearings consisting of high damping rubber bearings and lead rubber bearings are taken into account in the analysis models. The results showed that the failure probability of the bridge system is dominated by the bridge columns over the isolation bearings.

Previous studies have mainly focused on constructing fragility curves for bridge structures equipped with and/or without laminate/lead rubber bearings. However, a study on the seismic performance of bridge structures considering a variation of mechanical properties of base isolators is not well-documented and therefore, needs to be further scrutinized and clarified.

The purpose of this study is to derive fragility curves for $\mathrm{RC}$ bridge piers of a continuous steel box girder bridge located in Seoul, South Korea and to compare the seismic vulnerability of such bridges in the cases of different mechanical properties of LRBs. In order to achieve this goal, the finite element framework OpenSees [13] is utilized to implement the bridge model analyses. A series of 20 worldwide recorded ground motions is used for nonlinear dynamic response analyses. A damage index is proposed based on the displacement ductility ratio presented in FHWA [14]. Four damage states, namely slight, moderate, extensive, and collapse are defined based on the damage indices. From the observation of damage levels, fragility curves for the bridge piers are obtained by using the maximum likelihood estimation [3]. In addition, the influence of mechanical properties of LRBs on the seismic fragility curves of the bridges is thoroughly investigated in this research. Moreover, the seismic response of bridge piers with different heights is also considered.

\section{Bridge configuration}

The selected case study bridge is a seven-span continuous steel box girder bridge supported by circular RC single column piers. The length of the first and the last three spans 


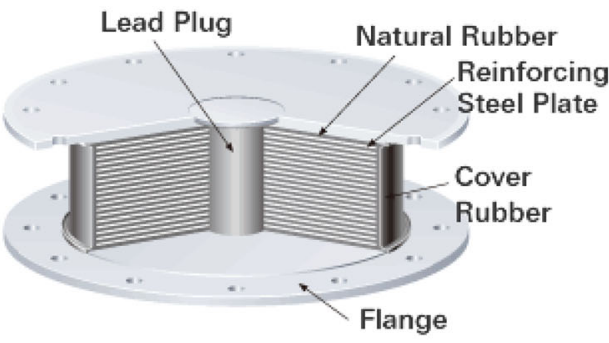

(a)

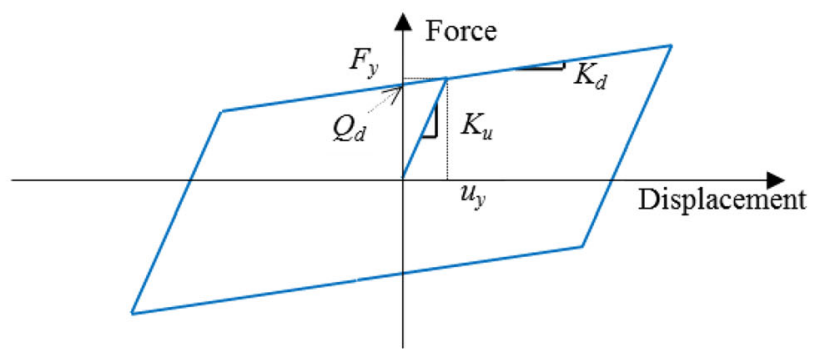

(b)

Figure 6. LRB (a) and its force-deformation relationship (b).
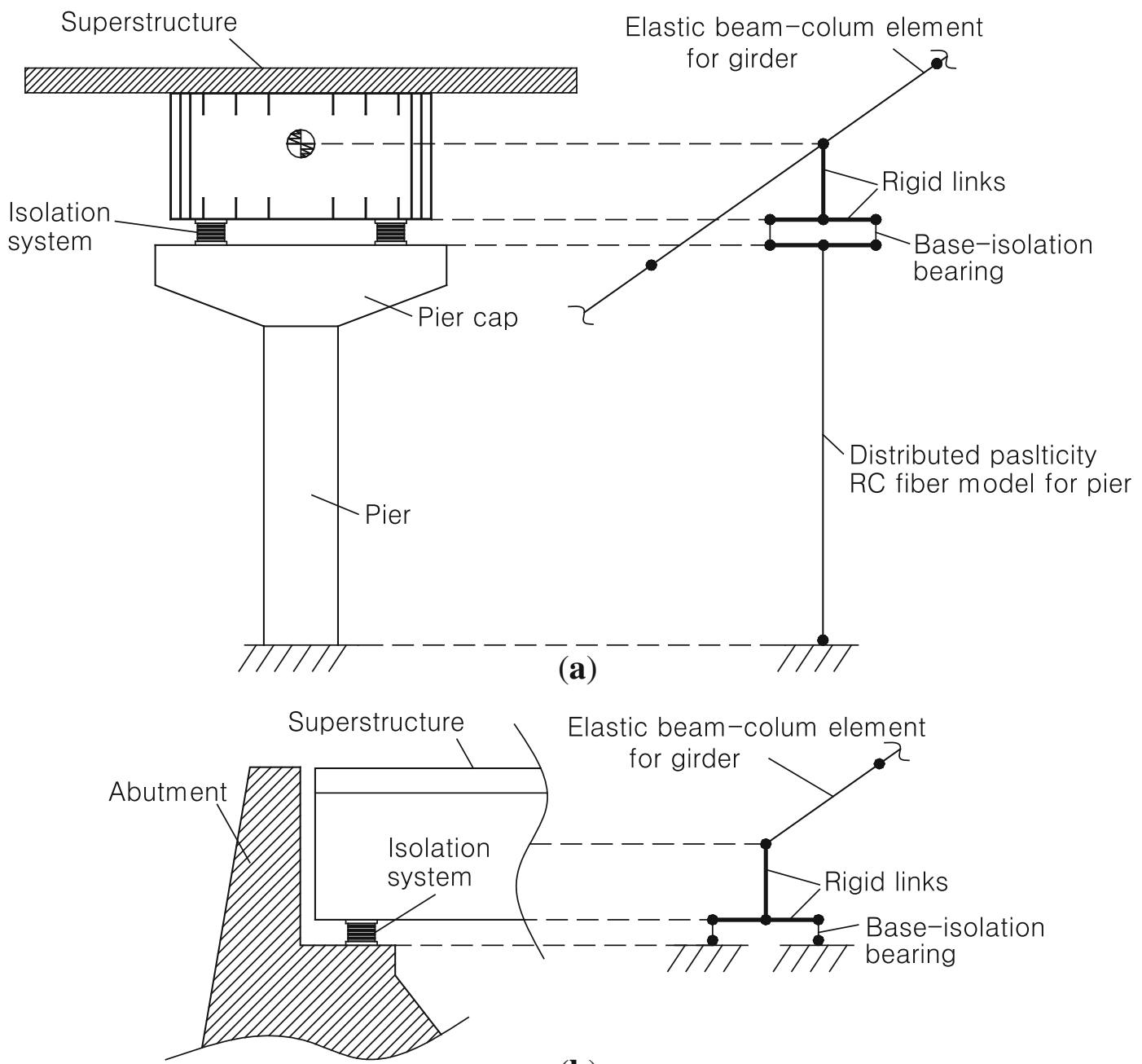

(b)

Figure 7. Modelling scheme of the isolated bridge in OpenSees: (a) pier-girder and (b) abutment-girder connection.

is $50 \mathrm{~m}$, the length of the second, third and fourth spans is $52.8 \mathrm{~m}, 62.0 \mathrm{~m}$, and $54.5 \mathrm{~m}$, respectively, as shown in figure 1. The columns height are varied from $10.4 \mathrm{~m}$ for pier P1, $8.75 \mathrm{~m}$ for pier $\mathrm{P} 2,6.8 \mathrm{~m}$ for pier $\mathrm{P} 6$ and $6.5 \mathrm{~m}$ for piers $\mathrm{P} 3, \mathrm{P} 4$, and $\mathrm{P} 5$. The cross-sectional diameter of all pier-columns is $1.6 \mathrm{~m}$. The cross-sectional dimensions of the bridge girder and the column are depicted in figures 2 and 3 , respectively. 
Table 3. Mechanical properties of LRBs with various elastic stiffness.

\begin{tabular}{lrrr}
\hline & LRB- & \multicolumn{1}{c}{ LRB- } & \multicolumn{1}{c}{ LRB- } \\
Parameter & \multicolumn{1}{c}{ K1 } & \multicolumn{1}{c}{ K2 } & \multicolumn{1}{c}{ K3 } \\
\hline Elastic stiffness, $K u,(\mathrm{KN} / \mathrm{m})$ & 40,000 & 20,000 & 10,000 \\
Post yield stiffness, $K d,(\mathrm{KN} / \mathrm{m})$ & 2,000 & 2,000 & 2,000 \\
Characteristic strength, $Q d,(\mathrm{KN})$ & 140 & 135 & 120 \\
Yield strength, $F y,(\mathrm{KN})$ & 150 & 150 & 150 \\
\hline
\end{tabular}

Table 4. Mechanical properties of LRBs with various yield strength.

\begin{tabular}{lrrr}
\hline Parameter & LRB-S1 & LRB-S2 & LRB-S3 \\
\hline Elastic stiffness, $K u,(\mathrm{KN} / \mathrm{m})$ & 20,000 & 20,000 & 20,000 \\
Post yield stiffness, $K d,(\mathrm{KN} / \mathrm{m})$ & 2,000 & 2,000 & 2,000 \\
Characteristic strength, $Q d,(\mathrm{KN})$ & 540 & 270 & 90 \\
Yield strength, $F y,(\mathrm{KN})$ & 600 & 300 & 100 \\
\hline
\end{tabular}

\section{Numerical modelling}

\subsection{Material model}

OpenSees provides various uniaxial material models for concrete and steel materials. For this research, the concrete 02 model, which adopted the Kent-Park model [15] is applied for confined and unconfined concrete of the bridge piers. The steel02 model, which adopted the MenegottoPinto model [16] is used for modelling of reinforcing bars in the bridge piers. These two models have taken into account the nonlinear characteristics of materials. The moment-curvature relationships of all column sections are illustrated in figure 3. Properties of the concrete and the steel are described in tables 1 and 2, respectively. In table $1, f_{p c}$ is the concrete compressive strength at 28 days, $\varepsilon_{c o}$ is the concrete strain at maximum strength, $f_{p c u}$ is the concrete crushing strength, $\varepsilon_{u}$ is the concrete strain at crushing strength, $f_{t}$ is the concrete tensile strength, and $E_{t s}$ is the tension softening stiffness. In table $2, F_{y}$ is the yield strength, $\mathrm{E}_{\mathrm{s}}$ is the initial elastic stiffness, $b$ is the strainhardening ratio, $R_{O}$ is a constant between 10 and 20, $C_{R I}$ and $C_{R 2}$ are coefficients. Figure 4 shows the stress-strain relationship of the concrete and steel material models.

\subsection{Elements modelling}

Under a strong seismic loading, the bridge piers may suffer from experiencing inelastic behaviour. In order to achieve an accurate representation of plasticity and nonlinear behaviour along the plasticity model (nonlinearBeamColumn element in OpenSees) with the fiber section modelling scheme is used. The concrete02 and steel02 constitutive models areassigned to concrete and steel fibers, respectively. Figure 5 illustrates the fiber section model for the bridge pier components.

Table 5. Natural periods of the studied bridge with and without LRBs (unit: seconds).

\begin{tabular}{lcccccrc}
\hline & & \multicolumn{4}{c}{ Base isolation } \\
\cline { 3 - 7 } Vibration mode & Non-isolated & LRB-K1 & LRB-K2 & LRB-K3 & LRB-S1 & LRB-S2 & LRB-S3 \\
\hline 1st & 0.88 & 1.10 & 1.21 & 1.39 & 1.21 & 1.21 & 1.21 \\
2nd & 0.70 & 0.90 & 1.03 & 1.24 & 1.03 & 1.03 & 1.03 \\
3rd & 0.57 & 0.77 & 0.88 & 1.11 & 0.88 & 0.88 & 0.88 \\
\hline
\end{tabular}
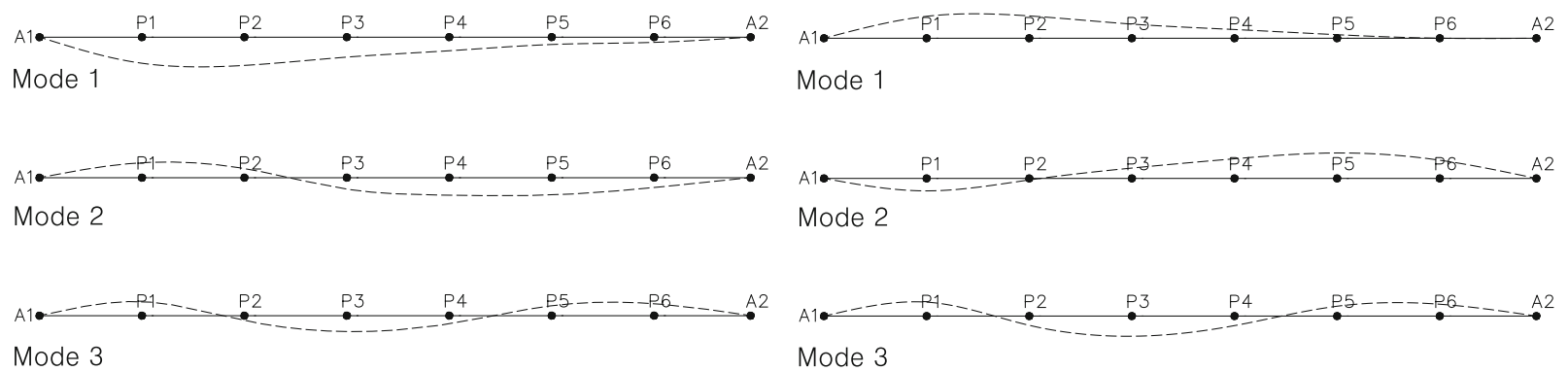

(a)

Figure 8. The first three mode shapes of the bridge models. (a) Non-isolated bridge. (b) Base isolation bridge. 
Table 6. List of selected ground motion records.

\begin{tabular}{|c|c|c|c|c|c|}
\hline No. & Earthquake & Year & Station & Mag. $\left(M_{w}\right)$ & PGA $(g)$ \\
\hline 1 & Cape Town, S. Africa & 1969 & Cape Town & 6.3 & 0.384 \\
\hline 2 & Duzce, Turkey & 1999 & Duzce & 7.1 & 0.727 \\
\hline 3 & Hector, USA & 1999 & North Palm Springs & 7.1 & 0.265 \\
\hline 4 & Chichi, Taiwan & 1999 & Taichung & 7.6 & 0.352 \\
\hline 5 & El-Centro, USA & 1940 & Imperial Valley Irrigation Distr. & 6.9 & 0.400 \\
\hline 6 & El-Centro, USA & 1940 & Imperial Valley Irrigation Distr. & 6.9 & 0.274 \\
\hline 7 & Imperial Valley, USA & 1979 & Mexicali, Mexico & 6.5 & 0.237 \\
\hline 8 & Imperial Valley, USA & 1979 & El Centro, CA & 6.5 & 0.363 \\
\hline 9 & Kobe, Japan & 1995 & Nishi-Akashi & 6.9 & 0.509 \\
\hline 10 & Kobe, Japan & 1995 & Kakogawa & 6.9 & 0.243 \\
\hline 11 & Loma Prieta, USA & 1989 & Capitola & 7.0 & 0.528 \\
\hline 12 & Northridge, USA & 1994 & White Oak Covenant Church & 6.7 & 0.415 \\
\hline 13 & Northridge, USA & 1994 & Reseda & 6.7 & 0.410 \\
\hline 14 & Landers, USA & 1992 & Joshua Tree & 7.3 & 0.244 \\
\hline 15 & Kocali, Turkey & 1999 & KOER & 7.4 & 0.312 \\
\hline 16 & Irpinia, Italy & 1980 & Irpinia & 6.9 & 0.351 \\
\hline 17 & San Fernando, USA & 1971 & Pacoima Dam & 6.6 & 0.209 \\
\hline 18 & Tabas, Iran & 1978 & MHUD-Bajestan & 7.8 & 0.899 \\
\hline 19 & Manjil-Rudbar, Iran & 1990 & BHRC-Abbar & 7.4 & 0.514 \\
\hline 20 & Hendek-Akyazi, Turkey & 2000 & KOER & 5.8 & 0.357 \\
\hline
\end{tabular}

On the other hand, the girder is assumed to remain elastic during seismic excitations. Hence, the elasticBeamColumn element is adopted to model the bridge girder components. Some characterized quantities of the girder section such as cross-sectional area, torsional moment of inertia of crosssection, and second moments of area are calculated based on the section given in figure 2. Besides, the element mass per unit length of the superstructure is also imposed to perform the dynamic analysis procedure of the bridge.

For the isolated bridge, one of the most important components of the structure is the connections between substructures and superstructure. On the pier-caps and abutments, two isolator systems in terms of LRBs are installed to accommodate deformations of the superstructure during earthquake events. The behaviour of an LRB under shear forces is assumed to bea bilinear model that is characterized by typical features: initial stiffness $\left(K_{u}\right)$, postyield stiffness $\left(K_{d}\right)$ and yield strength $\left(F_{y}\right)$ or characteristic strength $\left(Q_{d}\right)$. Figure 6 shows the sketch of the elastomericBearing element, which was distinctly designed to apply for modelling a base isolator in OpenSees. Figure 7 shows the modelling of structural components of the based isolated bridges. In order to assess the effect of the mechanical properties of LRB on seismic responses of the bridge structures, we have selected the initial stiffness of LRB as the parameter. Three different values of the initial stiffness of LRB with $40,000 \mathrm{KN} / \mathrm{m}, 20,000 \mathrm{KN} / \mathrm{m}$, and 10,000 KN/ $\mathrm{m}$ are considered and referred to as LRB-K1, LRB-K2, and LRB-K3, respectively, as shown in table 3. Likewise, three different levels of the yield strength of LRB with $600 \mathrm{KN}$, $300 \mathrm{KN}$, and $100 \mathrm{KN}$ are considered and referred to as LRB-S1, LRB-S2, and LRB-S3, respectively, as shown in

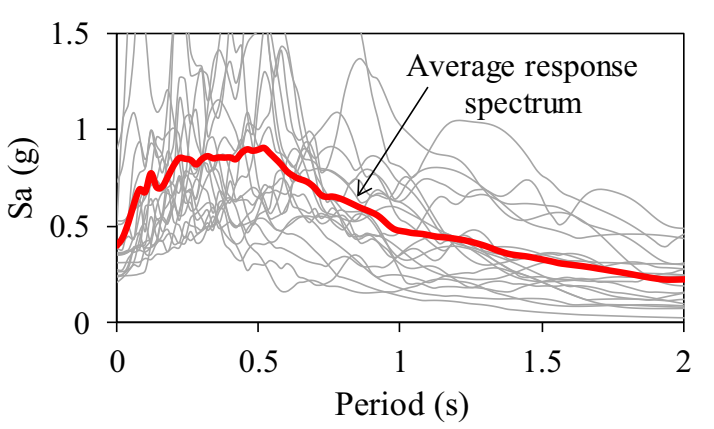

Figure 9. Acceleration response spectra of 20 ground motions.

table 4. Note that the technical properties of LRB are referred in the LRB catalogues of Unison eTech Co., Ltd [17] and are adjusted for a simulated facilitation purpose.

For the non-isolated bridge, the continuous superstructure is rigidly connected to the columns. In OpenSees, this connection is modelled by rigid-link elements. It should be noted that the effect of abutments, as well as soil-structure interaction on performances of the bridge, is neglected in this research. Therefore, the piers are modelled to be fixed to the ground, while the abutment-superstructure connections are modelled as pinned restraints.

\section{Eigenvalue analysis}

Table 5 shows the first three natural periods of the studied bridge without based isolators and with six cases of different mechanical properties of LRB. Due to large deformation 

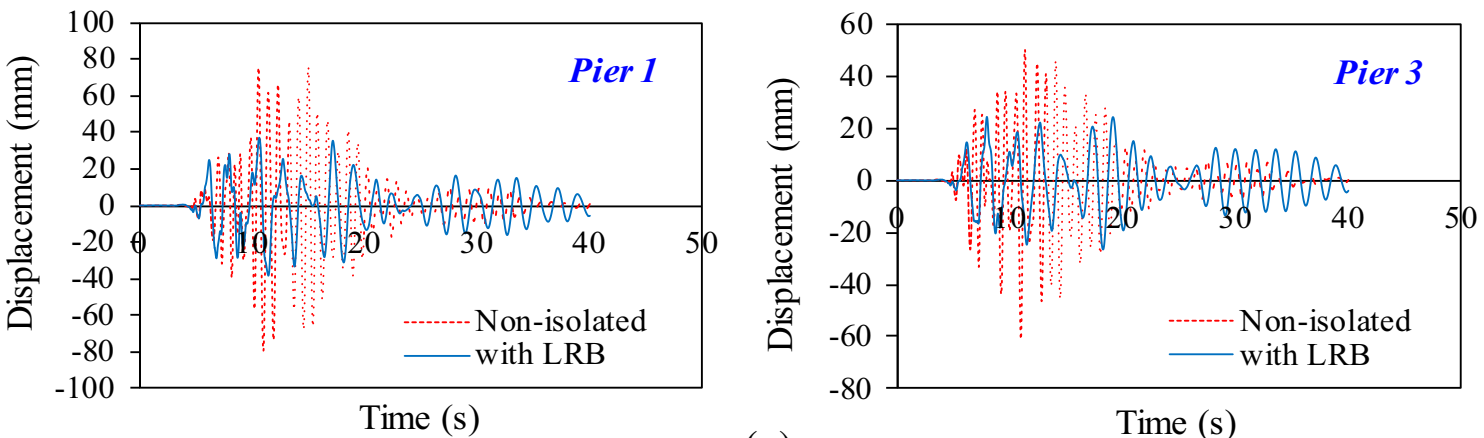

(a)

Time (s)
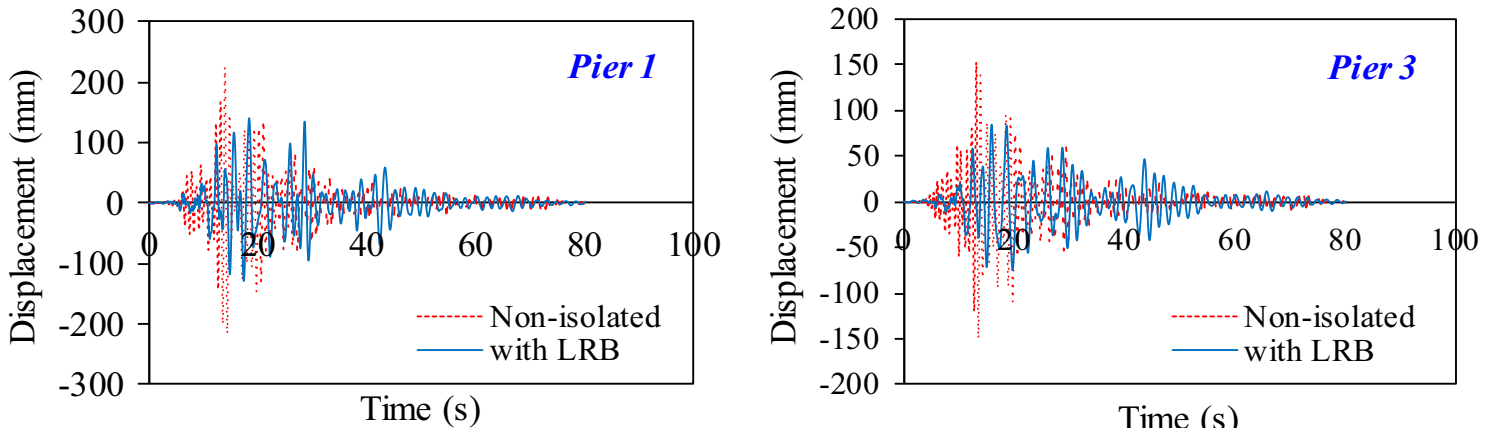

(b)

Figure 10. Displacement response of the bridge pier P1 and P3 with and without LRBs. (a) 1995 Kobe earthquake. (b) 1989 Loma Prieta earthquake.
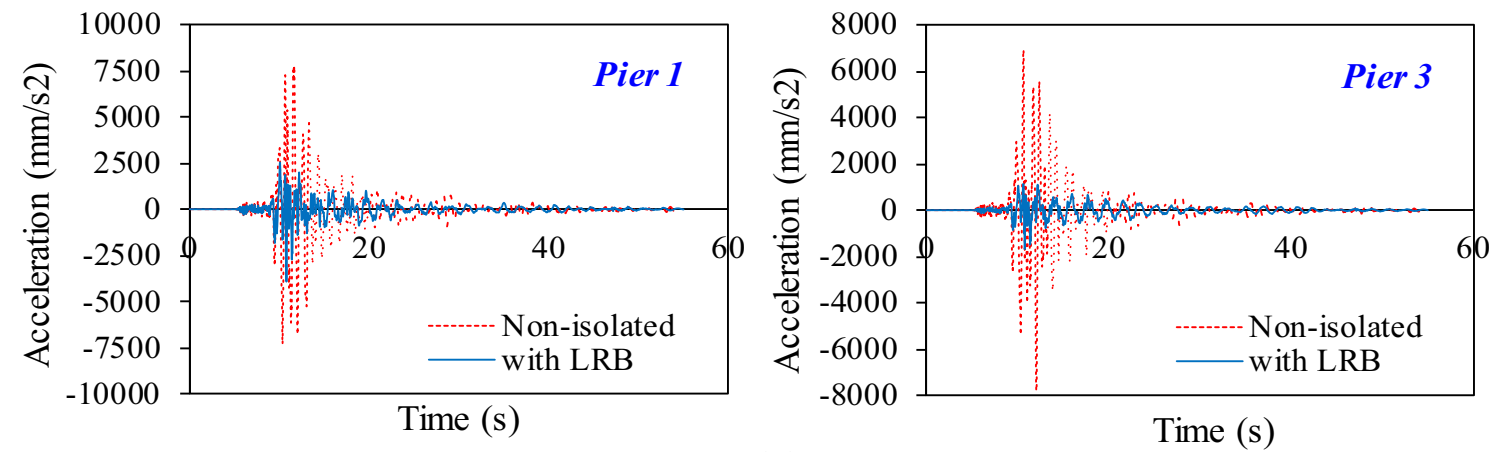

(a)
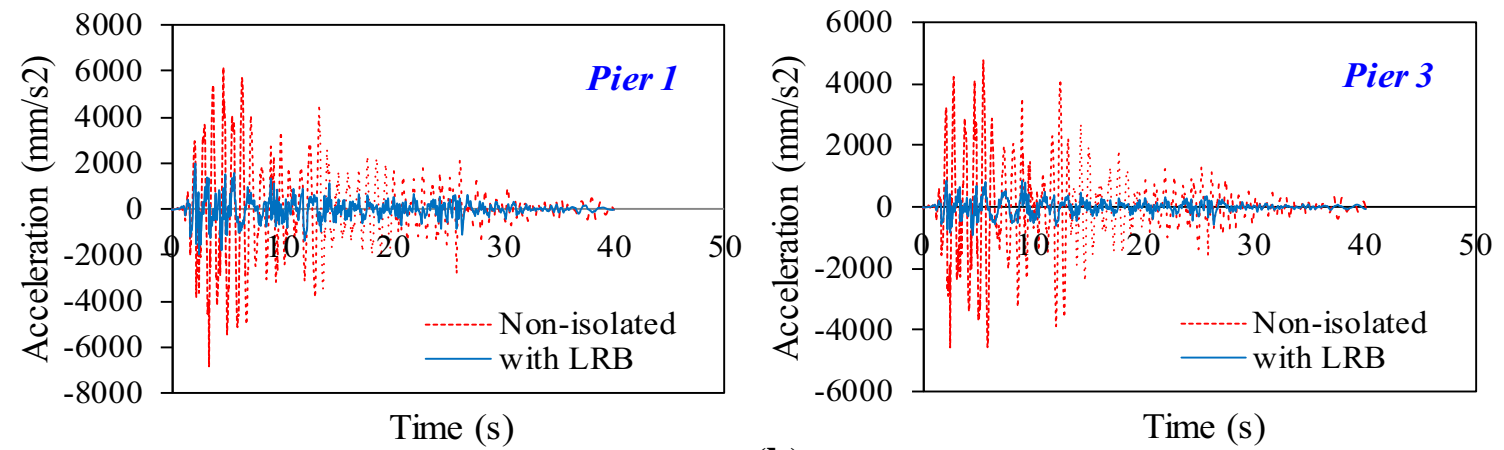

(b)

Figure 11. Acceleration response of the bridge pier P1 and P3 with and without LRBs. (a) 1999 Duzce earthquake. (b) 1940 El Centro earthquake. 

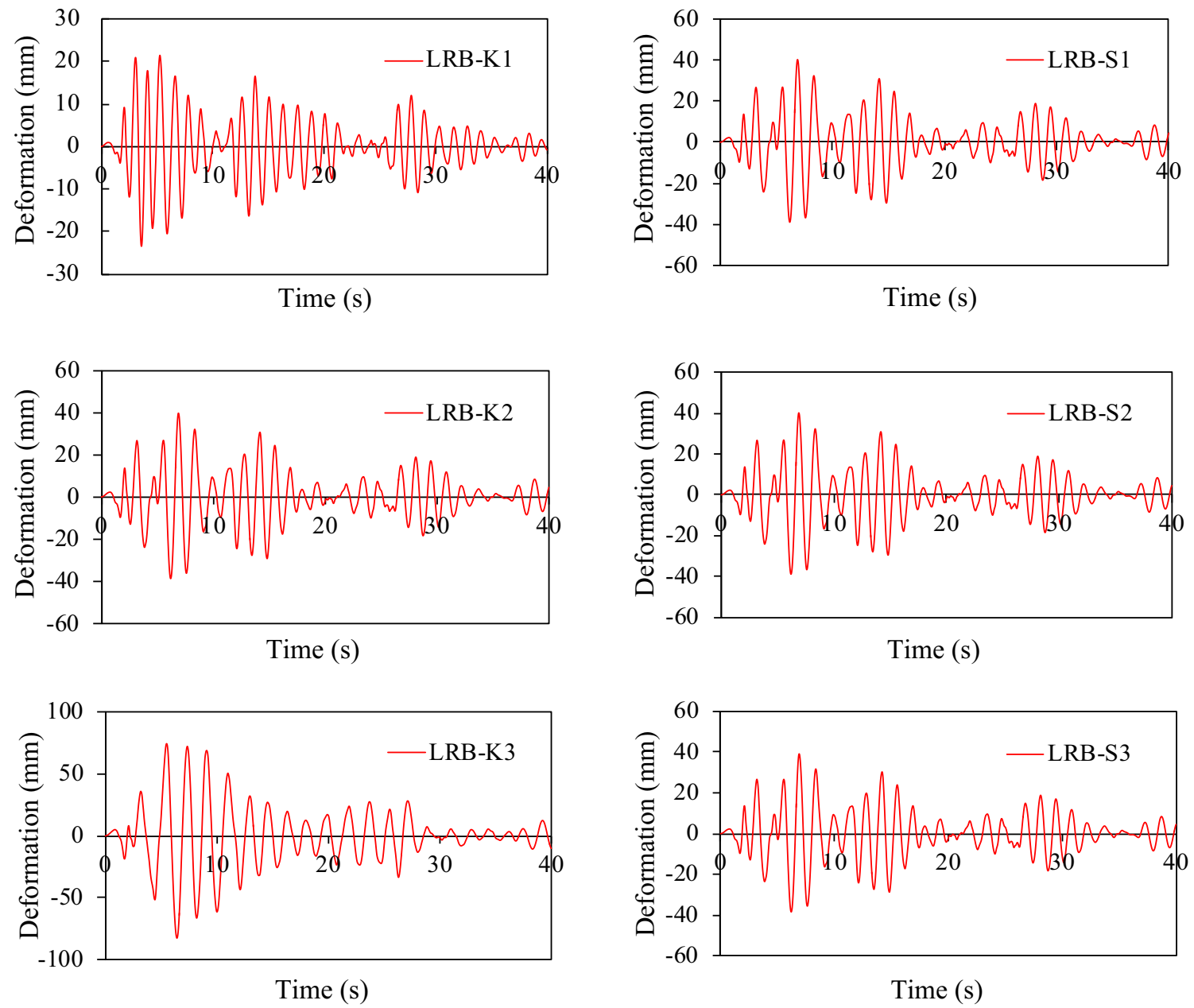

(a)

(b)

Figure 12. Shear deformation of LRB under the 1940 El Centro earthquake. (a) Variation of LRB's elastic stiffness. (b) Variation of LRB's yield strength.

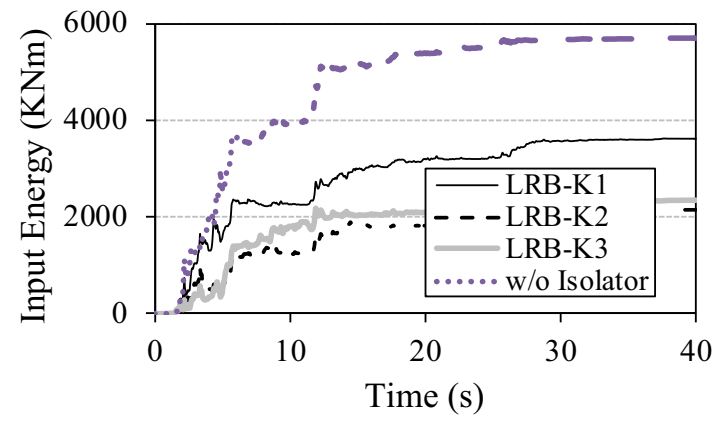

(a)

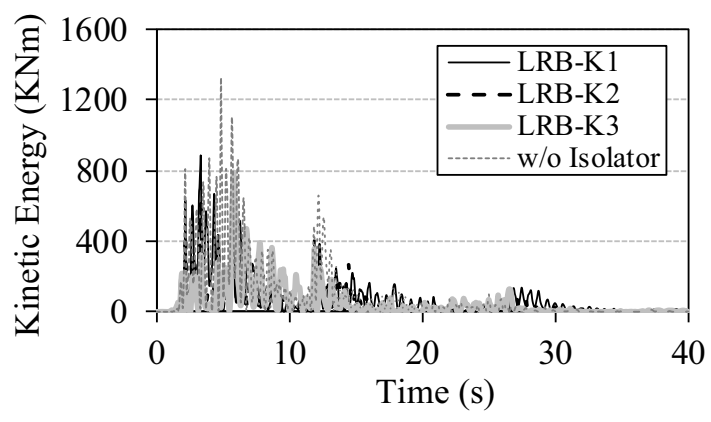

(b)

Figure 13. Energy time histories for the bridge with variation of LRB's stiffness under the 1940 El Centro earthquake. (a) Input energy. (b) Kinetic energy.

capacity of LRBs, the inertial force in the girder is reduced and all vibration periods are approximately increased by 1.5 times compared with those of the non-isolated bridge. The result also indicated that decreasing the initial stiffness of
LRB increases vibration periods of the bridge and vice versa. This can be attributed to the reason that the lesser the stiffness of LRB, the larger will be the relative deformation between the girder and piers. Therefore, the inertial force in the 
Table 7. Qualitative damage states of bridge structures (adopted from FEMA, 2003).

\begin{tabular}{|c|c|}
\hline Damage state & Description of damage in a bridge structure \\
\hline None-damage (DS0) & No damage \\
\hline Slight damage (DS1) & $\begin{array}{l}\text { Minor cracking and spalling of the abutments, cracks in shear keys at abutments, minor spalling and cracks at } \\
\text { hinges, minor spalling of the column (damage requires no more than cosmetic repair), or minor cracking of the } \\
\text { deck }\end{array}$ \\
\hline $\begin{array}{l}\text { Moderate damage } \\
\text { (DS2) }\end{array}$ & $\begin{array}{c}\text { Any column experiencing moderate (shear cracks) cracking and spalling (column still sound structurally), } \\
\text { moderate movement of the abutment }(<50 \mathrm{~mm}) \text {, extensive cracking and spalling of shear keys, any connection } \\
\text { having cracked shear keys or bent bolts, keeper-bar failure without unseating, rocker-bearing failure, or } \\
\text { moderate settlement approach }\end{array}$ \\
\hline $\begin{array}{l}\text { Extensive damage } \\
\text { (DS3) }\end{array}$ & $\begin{array}{l}\text { Any column degrading without collapse-shear failure (column structurally unsafe), significant residual movement } \\
\text { at connections, or major approach settlement, vertical offset of the abutment, differential settlement at } \\
\text { connections, shear-key failure at abutment }\end{array}$ \\
\hline $\begin{array}{l}\text { Complete damage } \\
\text { (DS4) }\end{array}$ & $\begin{array}{l}\text { Any column collapsing and connection losing all bearing support, which may lead to imminent deck collapse or } \\
\text { tilting of substructure caused by foundation failure }\end{array}$ \\
\hline
\end{tabular}

Table 8. Proposed damage states of the studied bridges and indices of other references.

\begin{tabular}{|c|c|c|c|c|c|c|}
\hline & \multirow[b]{2}{*}{ Component } & \multirow[b]{2}{*}{ Demand parameter } & \multicolumn{4}{|c|}{ Threshold value } \\
\hline & & & $\begin{array}{l}\text { Slight } \\
\text { (DS1) }\end{array}$ & $\begin{array}{l}\text { Moderate } \\
\text { (DS2) }\end{array}$ & $\begin{array}{l}\text { Extensive } \\
\text { (DS3) }\end{array}$ & $\begin{array}{l}\text { Collapse } \\
\text { (DS4) }\end{array}$ \\
\hline \multirow[t]{6}{*}{ This study } & Pier P1 & Displacement ductility & 1.0 & 1.2 & 1.9 & 4.7 \\
\hline & Pier P2 & ratio & 1.0 & 1.3 & 2.0 & 4.8 \\
\hline & Pier P3 & & 1.0 & 1.3 & 2.0 & 5.2 \\
\hline & Pier P4 & & & & & \\
\hline & Pier P5 & & & & & \\
\hline & Pier P6 & & 1.0 & 1.3 & 2.0 & 5.1 \\
\hline $\begin{array}{l}\text { Alam et al [12], Hwang et al } \\
\text { [21] }\end{array}$ & Pier & $\begin{array}{l}\text { Displacement ductility } \\
\text { ratio }\end{array}$ & 1.0 & 1.2 & 1.76 & 4.76 \\
\hline
\end{tabular}

superstructure is also mitigated and produced the smaller vibration period. Meanwhile, a variation of the yield strength of LRBs (from $600 \mathrm{KN}$ to $100 \mathrm{KN}$ ) does not change the natural periods of the bridge structure. This consequence is caused by the reason that the relative displacement between girder and piers is unvarying due to the constant stiffness of LRB; consequently, the global stiffness and the inertial force generated in superstructure is also invariable. Figure 8 shows the first three vibration mode shapes of the non-isolated and base isolation bridges for illustrative purpose. It should be noted that P1 is the highest pier, hence, the fundamental mode produced the maximum horizontal displacement at the neighbourhood of pier P1.

\section{Procedure for developing seismic fragility curves}

In order to build up the fragility curves for the bridges, nonlinear time history analyses are carried out. The procedure for constructing fragility curves of the structure can be implemented by basic steps as given here. (i) Build up the structural model that takes into account nonlinear materials as well as the inelastic features of the elements (e.g. bridge columns).

(ii) Impose sets of ground motions with a wide range of seismic intensity measure (e.g. PGA) to the structural model in the transverse direction (Y-axis). In this study, 20 recorded ground accelerations are selected from the historic earthquake events and PGA of each ground motion is scaled from $0.1 \mathrm{~g}$ to $1.6 \mathrm{~g}$ with intervals of $0.1 \mathrm{~g}$. Then, obtain the maximum of components responses (e.g. displacement ductility of the columns).

(iii) Define the limit states of each component based on the damage index, which is expressed in terms of ductility ratio of columns.

(iv) Compute the sample rate of exceeding the limit state at each ground intensity level.

(v) Generate fragility curves based on fitting fragility functions to the observed data using the maximum likelihood estimate formulation [3].

A fragility function expresses the conditional probability that the demand on the structure reaches or exceeds the 


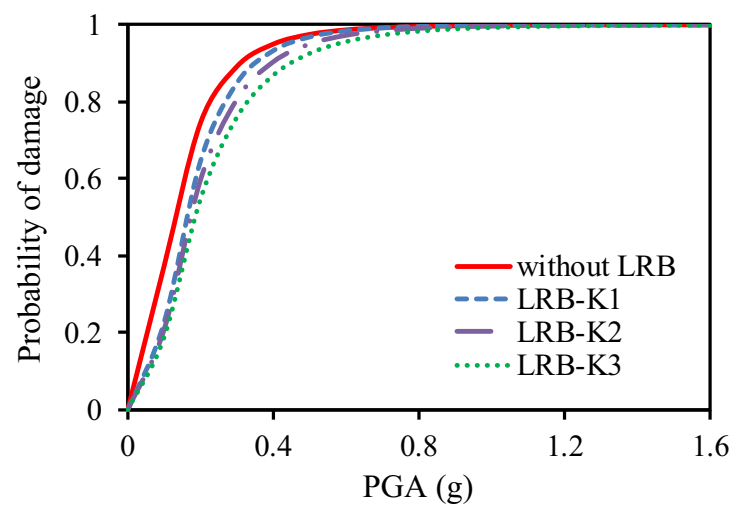

(a)

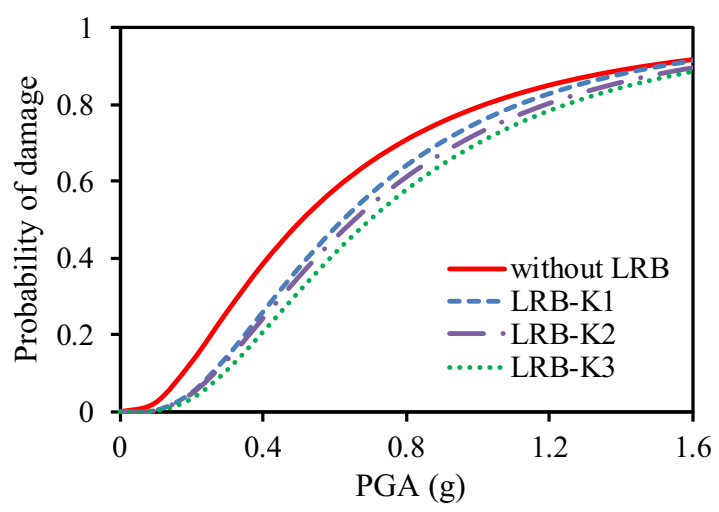

(c)

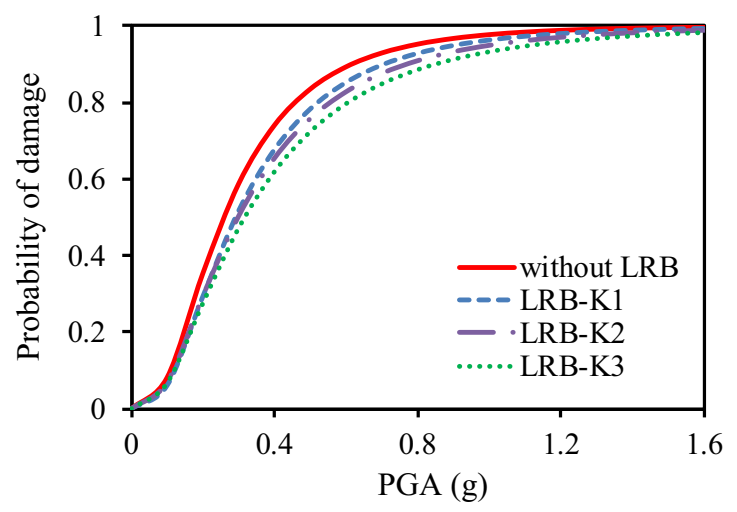

(b)

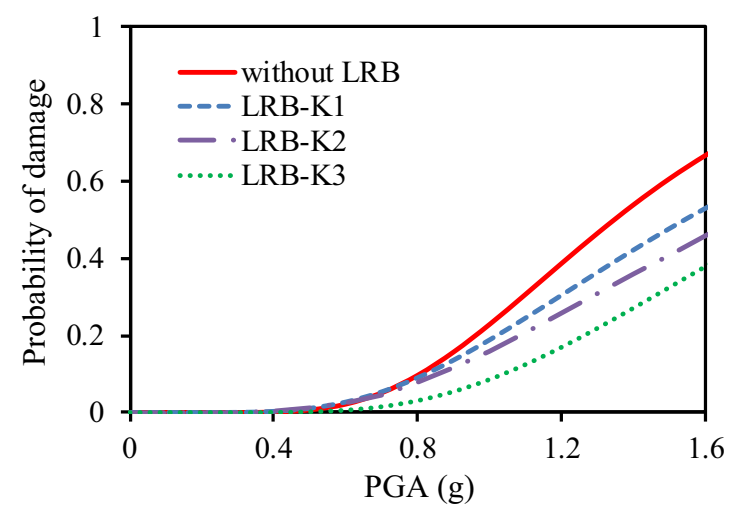

(d)

Figure 14. Fragility curves of bridge pier P1 for various elastic stiffness levels of LRB. (a) DS1, (b) DS2, (c) DS3, and (d) DS4.

structural capacity at a specific damage state given in a specific ground motion intensity. In this paper, the fragility function is assumed as a log-normal cumulative distribution function expressed by

$$
P[L S \mid I M=X]=\Phi\left(\frac{\ln X-\mu}{\beta}\right),
$$

where $P[L S \mid I M]$ is the probability of exceeding the limit state $(L S)$ at a given ground motion intensity measure (IM); $X$ is the value of ground motion in terms of peak ground acceleration (PGA); $\mu$ and $\beta$ are the median and standard deviation of $\ln X$, respectively; $\Phi(-)$ is standard normal cumulative distribution function.

\section{Input ground motions}

Seismic performance of the bridge is evaluated by using the nonlinear time history analyses, therefore the selection of input ground motions is important. In this paper, twenty ground accelerations are arbitrarily selected from the historic earthquake events on which database are provided by the Pacific Earthquake Engineering Research center [18] and Center for Engineering Strong Motion [19]. The variation of the ground motion profiles has been taken into account as a source of uncertainty for the seismic fragility analysis procedure. The magnitude and PGA of the suite of ground motions are described in table 6. Figure 9 shows the response spectra of the selected ground motions where the bold line indicates their average response spectrum. It should be noted that all ground motions are imposed to the bridge in the transverse direction ( $\mathrm{Y}$-axis) only and the dynamic responses of the bridge in the longitudinal and vertical directions are ignored.

\section{Seismic response of the bridge}

\subsection{Displacement response of bridge piers}

In this section, the seismic responses of bridge piers are presented in detail. Nonlinear time-history analyses are carried out for each of the twenty ground motions. The lateral displacement at the top of bridge piers is monitored during seismic excitations. Figure 10 shows that the lateral displacement time-history response of piers subjected to some representative earthquake events. Due to the presence of base isolators (e.g. LRBs), the top pier's displacement is significantly decreased compared with those of the non- 


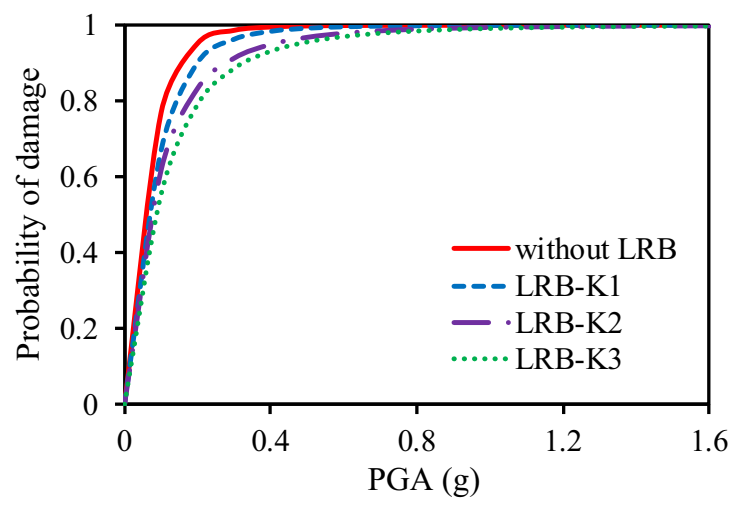

(a)

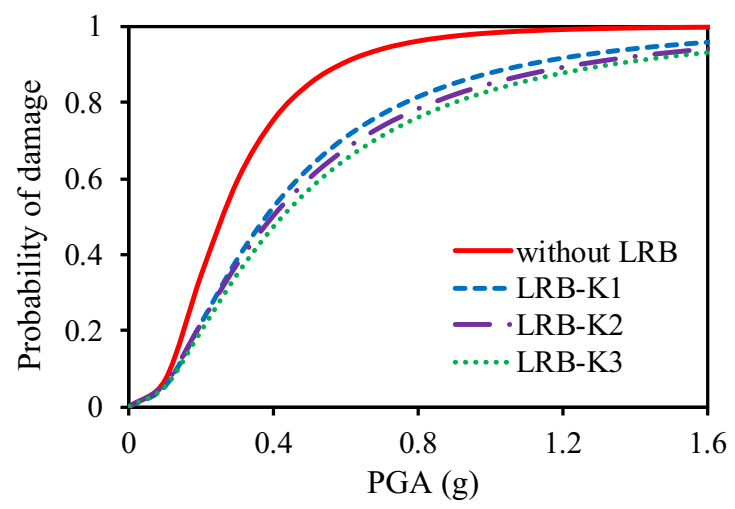

(c)

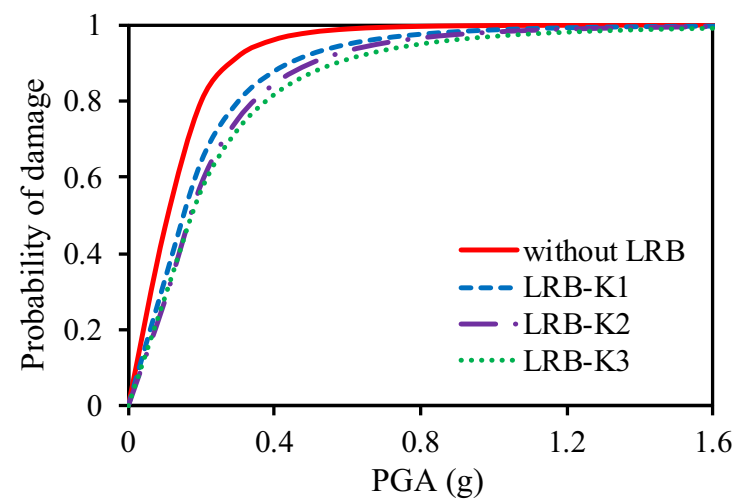

(b)

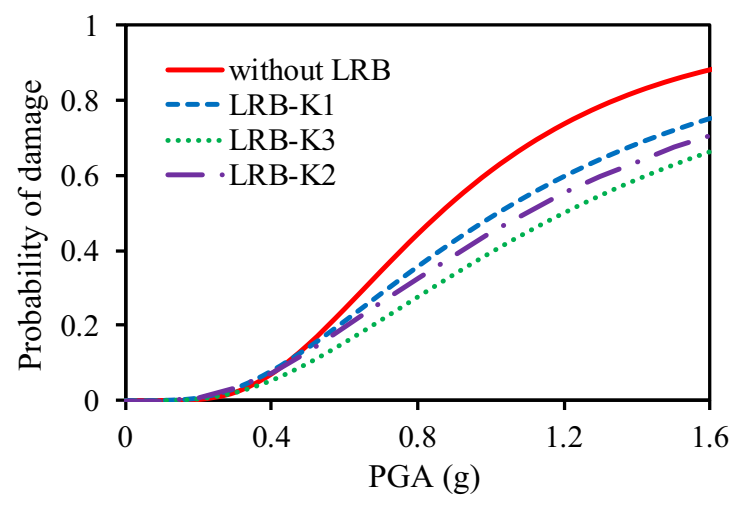

(d)

Figure 15. Fragility curves of bridge pier P3 for various elastic stiffness levels of LRB. (a) DS1, (b) DS2, (c) DS3, and (d) DS4.

isolated bridge piers. It should be noted that we do compare results of all cases of the bridge equipped with LRBs and non-isolated bridge models accounting for the selected 20 ground motions.

\subsection{Acceleration response of bridge piers}

Figure 11 shows the acceleration time-history response of the bridge piers P1 and P3 under representative ground motions. Similar to the displacement response, the acceleration response of the seismically-isolated bridge piers is found to be much smaller than those of the non-isolated bridge piers.

\subsection{Deformation response of LRBs}

Figure 12 shows the shear deformation of the LRBs installed on the top of pier P3 for considering the variation of LRB's mechanical properties (e.g. elastic stiffness and strength) subjected to the $1940 \mathrm{El}$ Centro earthquake. For the case of changing LRB's stiffness, it can be seen that lateral deformation of LRB is increased with the decrease of the elastic stiffness, as shown in figure 12(a). This means that the stiffer LRB yields the smaller shear deformation subjected to a specific shear force (e.g. a seismic excitation). Meanwhile, by reducing the strength of LRBs, the shear deformation of LRBs was not varied, as shown in figure 12(b). It can be attributed that the constancy of the elastic stiffness and post-yield stiffness of LRB yields the same shear deformation under a given shear force. A similar result is also observed from the other ground motions.

\subsection{Energy time-history}

Figure 13 shows the input energy and kinetic energy generated in the bridge subjected to the 1940 El Centro earthquake. It can be seen that input energy generated from the earthquake for the base isolation bridge models is considerably reduced, the same trend is also observed for the kinetic energy formed in the structure. This is attributed to the reason that the LRB device shifts the natural period of the bridge structure beyond the predominant periods of earthquakes. Moreover, the seismic energy is dissipated and the seismic forces are restrained, transferring to the structure through the energy-dissipation mechanism of LRB systems. 


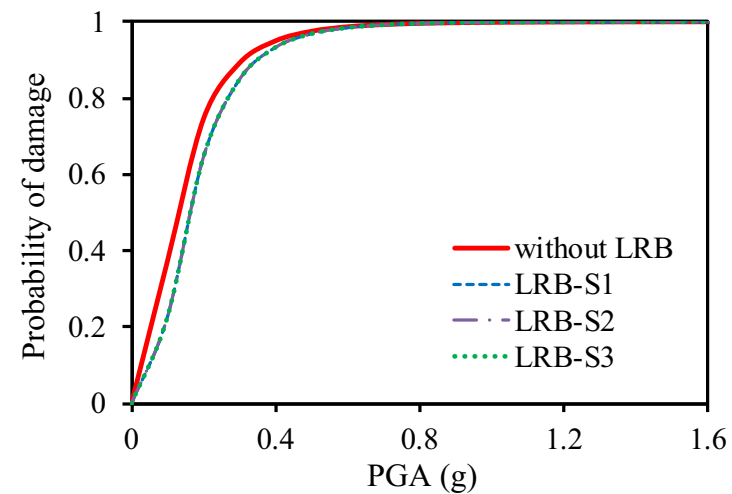

(a)

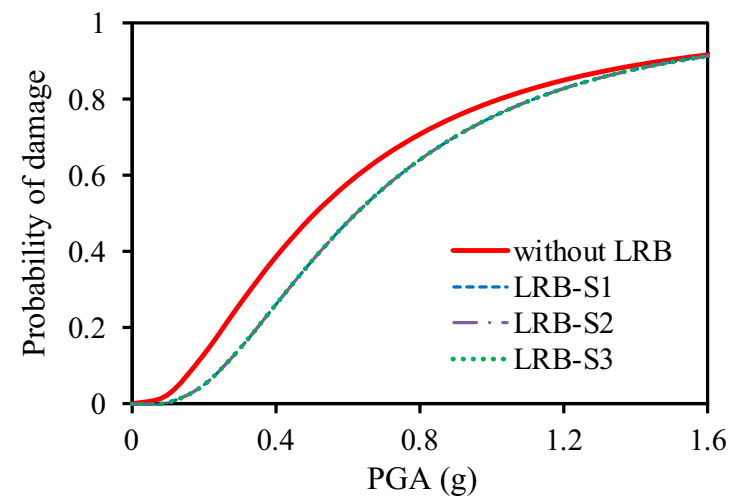

(c)

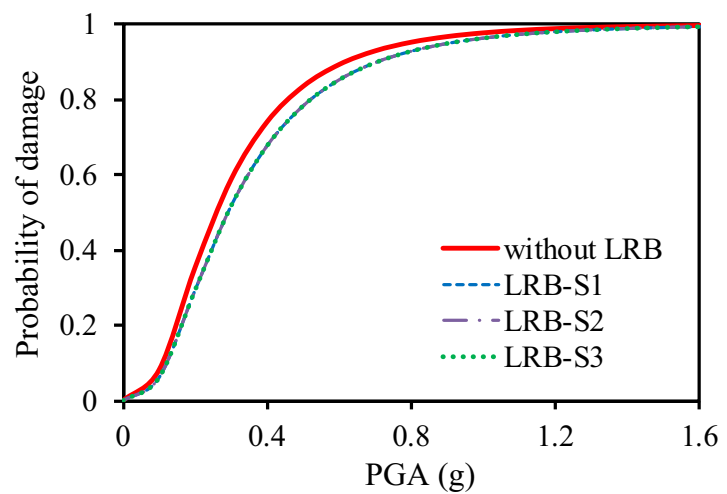

(b)

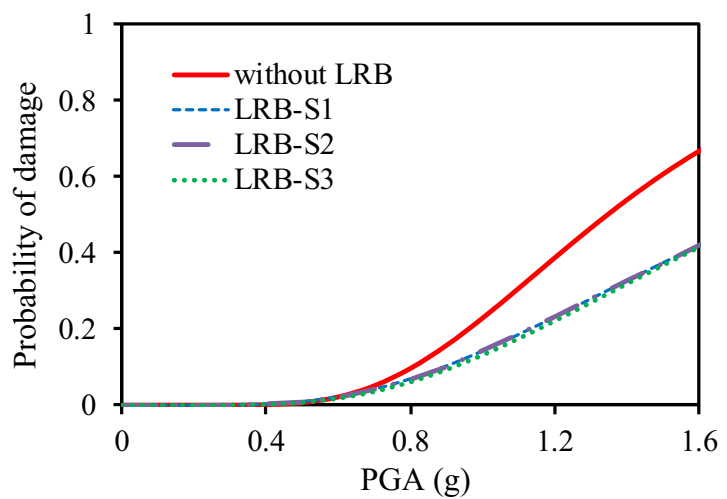

(d)

Figure 16. Fragility curves of bridge pier P1 for various yield strength levels of LRB. (a) DS1, (b) DS2, (c) DS3, and (d) DS4.

\section{Component limit states}

For bridge structures, some critical components such as pier-columns, isolated bearings and abutments are susceptible to seismic excitations. Therefore, studying on the seismic performances as well as damage states of these components is crucial in the vulnerability evaluation of the bridges. Due to the extremely important role of piers, the vulnerability of a pier will significantly effect on the load bearing capacity of the entire structure, especially under earthquake loadings. In this paper, we only focused on the limit states definition and fragility analysis procedure for the bridge columns, which is the most crucial member of the bridge structure.

For this study, we have adopted the definition of damage states based on column curvature ductility ratio $\left(\mu_{\phi}\right)$ and displacement ductility ratio $\left(\mu_{\Delta}\right)$ proposed in FHWA [14] for constructing fragility curves of bridge columns. This definition can be expressed as:

$$
\mu_{\phi}=1+\frac{\mu_{\Delta}-1}{3 \frac{l_{p}}{L}\left(1-0.5 \frac{l_{p}}{L}\right)} .
$$

Due to practical reasons, the damage states related to displacements are more facilitated than the curvature ductility. Equation (2) can be rewritten in terms of displacement ductility ratio as

$$
\mu_{\Delta}=1+3 \frac{l_{p}}{L}\left(1-0.5 \frac{l_{p}}{L}\right)\left(\mu_{\phi}-1\right)
$$

where $L$ is the length of the column, $l_{p}$ is the length of the plastic hinge given by the Eq. (4) hereafter, $d_{b}$ is the diameter of the column longitudinal reinforcing bar. It should be noted that curvature ductility ratio $\left(\mu_{\phi}\right)$ can be also defined as the ratio of the developing curvature in the piers due to bending moment to the curvature at the first yielding state of the reinforcement.

$$
l_{p}=0.08 L+9 d_{b}
$$

In general, each damage state represents a vulnerability level in structural components, as described in table 7 that is adopted from FEMA [20]. In this research, four damage states (DSs), namely slight, moderate, extensive, and collapse are defined in terms of the column displacement ductility ratio. Table 8 shows damage states of all bridge piers, which are related to the damage index. It should be noted that the piers P3, P4 and P5 are all of the same height, hence to be in the same value of the defined damage levels. In table 8, damage indices based on displacement ductility 


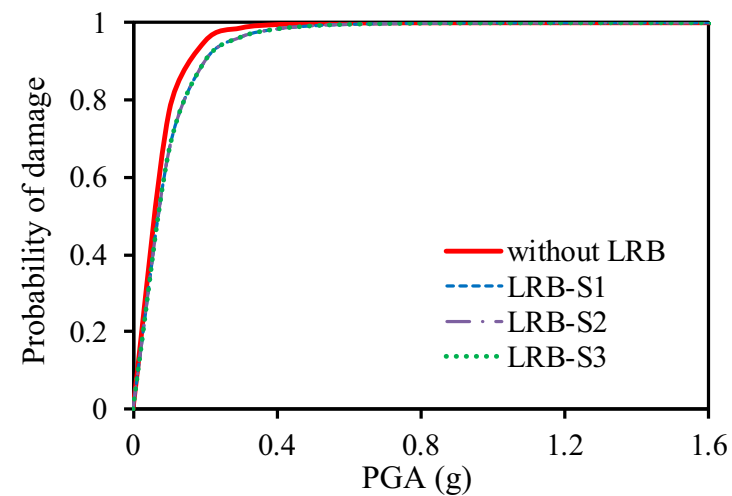

(a)

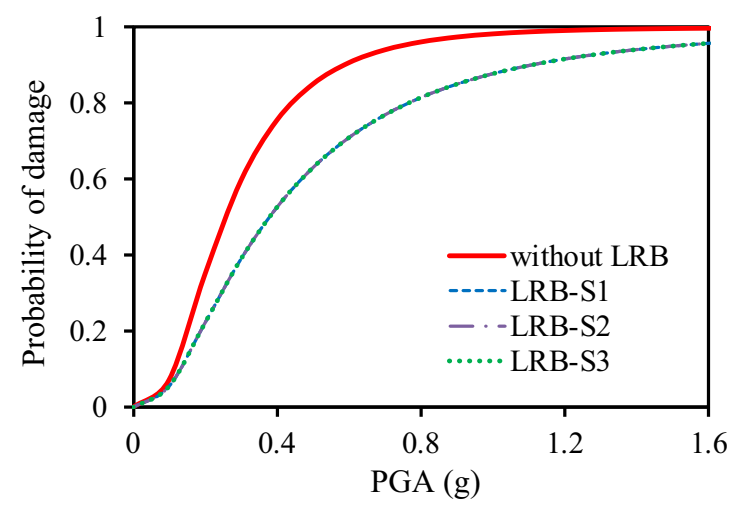

(c)

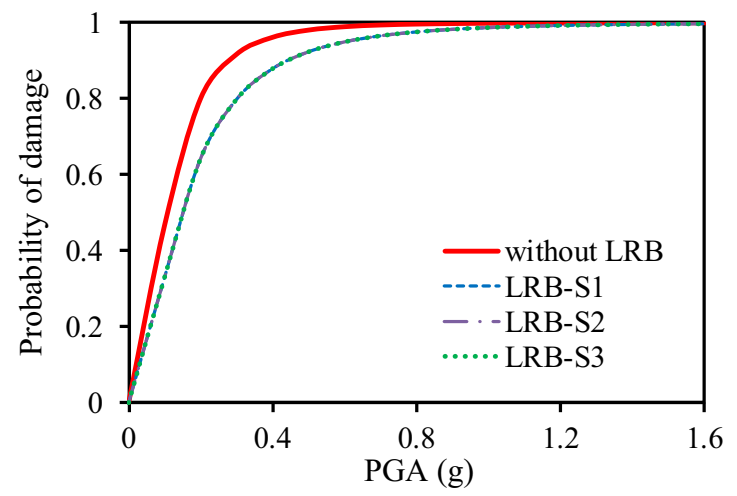

(b)

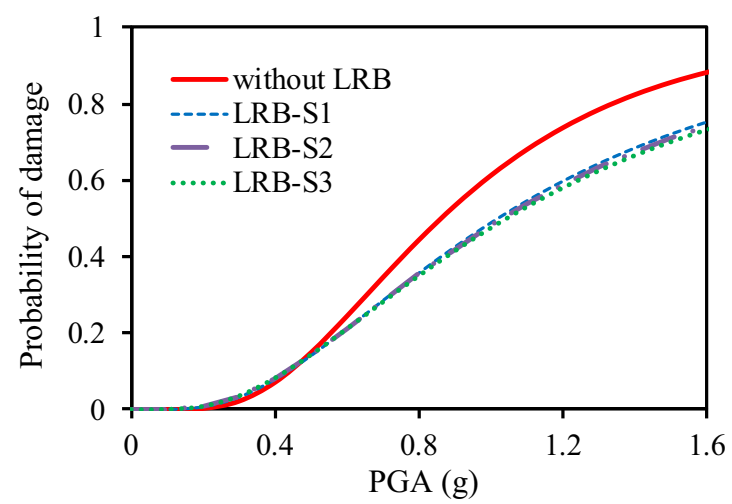

(d)

Figure 17. Fragility curves of bridge pier P3 for various yield strength levels of LRB. (a) DS1, (b) DS2, (c) DS3, and (d) DS4.

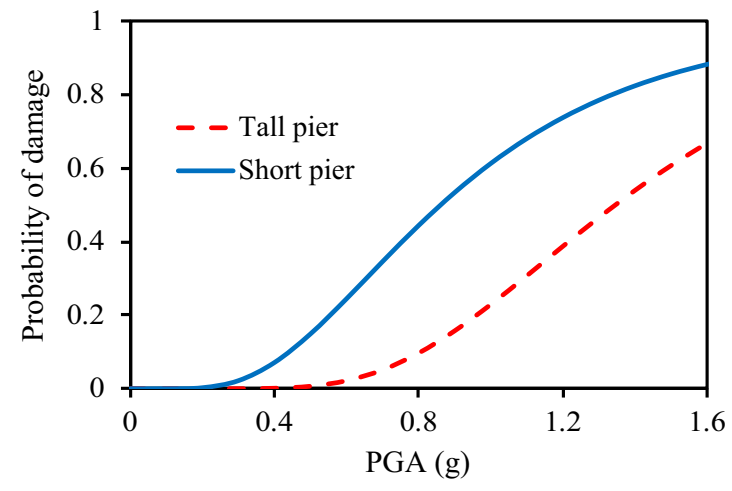

(a)

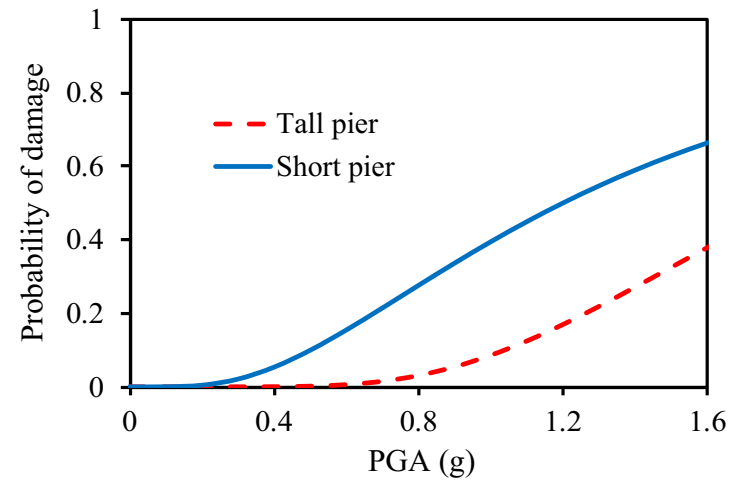

(b)

Figure 18. Comparison fragility curves between tall and short bridge piers in the DS4. (a) without base isolator and (b) with LRB.

ratio proposed by Hwang et al [21] and Alam et al [12] are also shown for comparison.

\section{Fragility curves}

Figures 14 and 15 show fragility curves of the bridge pier P1 and P3 with different initial stiffness levels of the LRBs and without base isolations. It should be noted that pier P1 and P3 typically represent for tall and short piers in the bridge model, respectively. The results reveal that reducing the initial stiffness of LRB reduces the seismic vulnerability of piers. Besides, the LRB-equipped bridge is also safer than a non-isolated bridge. Due to the energy dissipation capacity of the lead plug and the shear deformation capacity of the rubber layers in LRBs, lateral displacement at the top of the bridge piers is significantly reduced under seismic excitations. 
Figures 16 and 17 show fragility curves of the bridge pier P1 and P3 with different yield strength levels of LRB and without based isolation model. It implicates that the change in yield strength of LRB has trivially effected on the seismic behaviour of the piers. This result can be explained by the reason that the global stiffness of the bridge structure is not changed if the elastic stiffness of LBR is unvarying.

Figure 18 shows the comparison of fragility curves between the high pier (P1) and the short pier (P3) of the bridge considering with and without LRBs at the collapse damage state. It was found that the short pier is more vulnerable than the tall pier in the both seismically-isolated bridge and non-isolated bridge.

\section{Conclusions}

Seismic performance of a continuous steel box girder bridge with single-column RC piers is carried out by nonlinear time-history analysis method in OpenSees. In addition, the bridge considering base isolation devices is also modelled to identify the effect of the mechanical properties of LRB on seismic response of the bridge piers. Moreover, the seismic response of the piers with different height is also investigated. Based on the fragility analysis results, the following conclusions are drawn.

- By reducing the initial stiffness of the LRB, the bridge piers experience less vulnerability under seismic loading and vice versa. Nevertheless, maximum horizontal displacement of the superstructure is proportionally increased with the decrement of elastic stiffness of LRB during earthquakes. Therefore, an appropriate stiffness of LRB is the crucial point of seismically-isolated design for new bridges or improving the performance of existing bridges.

- There is a significant difference between seismic responses of the tall pier and short pier of the bridge in both cases with LRBs and without based isolators. The short bridge pier is more susceptible than the tall one during earthquake events. However, a comprehensive study on other types of bridge structures is warranted to assess this issue sufficiently.

- The effect of yielding strength of the LRB on the seismic performance of the bridge was found to be inconsiderable in terms of fragility functions.

- The level of damage probability for the non-isolated bridge is higher than those of the seismically-isolated one. A further study on the effect of soil-structure interaction on the fragility curves is necessary.

\section{Acknowledgements}

This work was supported by the National Research Foundation of Korea Grant funded by the Korean Government (NRF-2011-013-D00122).

\section{References}

[1] Billah A H M and Alam M S 2015 Seismic fragility assessment of highway bridges: a state-of-the-art review. Struct. Infrastruct. Eng.: Maint. Manag. Life-Cycle Des. Perform. 11(6): 804-832

[2] Shinozuka M, Feng M Q, Kim H K and Kim S H 2000 Nonlinear static procedure for fragility curve development. ASCE J. Eng. Mech. 126: 1287-1296

[3] Shinozuka, M, Feng M Q, Lee J and Naganuma T 2000 Statistical analysis of fragility curves. ASCE J. Eng. Mech. 126(12): 1224-1231

[4] Karim K R and Yamazaki F 2003 A simplified method of constructing fragility curves for highway bridges. Earthq. Eng. Struct. Dyn. 32: 1603-1626

[5] Park Y J and Ang A H S 1985 Mechanistic seismic damage model for reinforced concrete. ASCE J. Struct. Eng. 111: 722-739

[6] Choi E, DesRoches R and Nielson B G 2004 Seismic fragility of typical bridges in moderate seismic zones. Eng. Struct. 26: 187-199

[7] Kibboua A, Naili M, Benouar D and Kehila F 2011 Analytical fragility curves for typical Algerian reinforced concrete bridge piers. Struct. Eng. Mech. 39(3): 411-415

[8] Tavares D H, Suescun J R, Paultre P and Padgett J E 2013 Seismic fragility of a highway bridge in Quebec. ASCE J. Bridg. Eng. 18(11): 1131-1139

[9] Lee S M, Kim T J and Kang S L 2007 Development of fragility curves for bridges in Korea. KSCE J. Civil Eng. 11(3): 165-174

[10] Kim D K, Yi J H, Seo H Y and Chang C H 2008 Earthquake risk assessment of seismically isolated extradosed bridges with lead rubber bearings. Struct. Eng. Mech. 29(6): 689-707

[11] Ramanathan K, DesRoches R and Padgett J E 2010 Analytical fragility curves for multi span continuous steel girder bridges in moderate seismic zones. J. Transp. Research Board 2202: 173-182

[12] Alam M S, Bhuiyan A R and Billah A H M 2012 Seismic fragility assessment of SMA-bar restrained multi-span continuous highway bridge isolated with laminated rubber bearing in medium to strong seismic risk zones. Bull. Earthq. Eng. 10: 1885-1909

[13] Mazzoni S, McKenna F, Scott M H and Fenves G L 2007 OpenSees command language manual. Pacific Earthquake Engineering Research Center, University of California, Berkeley USA

[14] Federal Highway Administration (FHWA) 1995 Seismic Retrofitting Manual for Highway Bridges, Publication No. FHWA-RD-94-052, Department of Transportation, McLean, Virginia, USA

[15] Kent D C and Park R 1971 Flexural members with confined concrete. ASCE J. Struct. Div. 97(7): 1969-1990

[16] Menegotto M and Pinto P E 1973 Method of analysis for cyclically loaded reinforced concrete plane frames including changes in geometry and non-elastic behavior of elements under combined normal force and bending, IABSE Symposium of Resistance and Ultimate Deformability of Structures Acted on by Well-Defined Repeated Loads, Lisbon, Portugal, 13: 15-22

[17] Unison eTech Co., Ltd. 2014 Catalogue of Lead Rubber Bearing productions. Seoul, South Korea. http://unisonetech. en.ec21.com 
[18] Pacific Earthquake Engineering Research Center (PEER) 2015 Ground Motion Database. http://peer.berkeley.edu/ peer_ground_motion_database

[19] CESMD 2015 Center for Engineering Strong Motion Data. http://www.strongmotioncenter.org

[20] Federal Emergency Management Agency (FEMA) 2003 Multi-hazard Loss Estimation Methodology, Earthquake
Model HAZUS-MH MR3. Technical Manual, Washington DC, USA

[21] Hwang H, Liu J B and Chiu Y H 2001 Seismic fragility analysis of Highway bridges. Technical report MAEC RR-4, Center for Earthquake Research and Information, The University of Memphis, USA 